\title{
Prevalence of early repolarization pattern in young healthy men
}

\author{
Tarik Yildirim ${ }^{1}$, Eyup Avci $^{1}$, Seda Elcim Yildirim ${ }^{1}$, Gokhan Aydin ${ }^{1}$, Ahmet Dolapoglu ${ }^{2}$, \\ Adil Ozan Gokuc ${ }^{3}$
}

\begin{abstract}
Objective: Although the early re-polarization pattern known as a benign condition, it can result in idiopathic ventricular fibrillation and sudden cardiac death. In this study, we aimed to evaluate the prevalence of early repolarization pattern in young healthy men.
\end{abstract}

Methods and Patients: Four hundred fourteen young healthy men were enrolled in the study. PR intervals, QRS durations, QT intervals and corrected QT durations were measured from electrocardiographic records. Early repolarization pattern was defined as if an elevation $\mathrm{J}$-point was greater than $0,1 \mathrm{mV}$ according to the iso-electrical point.

Results: The prevalence of early repolarization pattern was $23,2 \%(n=96)$. Of these, we found early repolarization pattern in inferior, lateral and inferolateral leads with $14,7 \%, 2,2 \%$ and $6,3 \%$ respectively. There was a significant relation between heart rate and elevation of $\mathrm{J}$ point.

Conclusion: The prevalence of early repolarization pattern in young healthy men from Turkey was similar with the previously reported rates from different white populations.

Key Words: Early repolarization; Healthy men; Cardiology

\section{Introduction}

Early repolarization pattern (ER) is characterized by if elevation of $\mathrm{J}$ point, that is junction between the end of QRS complex and the beginning of the ST segment is greater than $0,1 \mathrm{mV}$. And it is required at least two subsequent derivation with ERP for diagnosis $(1,2)$. ER pattern on precordial derivation is benign condition but there is a strong relation between idiopathic ventricular fibrillation (VF) and ER pattern that seems in inferior and/or lateral leads (3-8). ER syndrome is defined as sudden cardiac death or occurrence of VF/ polymorphic ventricular tachycardia (VT) that cannot be explained in patient with ER pattern (9). Hypothermia, cocaine usage, Brugada syndrome and hypertrophic cardiomyopathy should be considered on differential diagnosis. Prevalence of ERP is $1-13 \%$ in normal population and $15-70 \%$ in patients with idiopathic VF $(10,11)$ The rate is $44 \%$ in young athletes and most of them have ascending ST segment pattern after J point (12). Existence of strong evidence between the sudden cardiac death and ER pattern and due to absent of literature knowledge about ER pattern of young men in Turkey, we aimed to find the rate of ER pattern among young healthy men in Turkey.

\section{Material and Methods}

After a protocol was approved by the ethical committee, we identified 414 young healthy men who applied for police high-school and had physical examination in cardiology department of Balikesir State Hospital. None of participants had diabetes mellitus and hypertension. The participant's ages were shown in table 1. Data were collected retrospectively including electrocardiographic (ECG) records. All subjects underwent 12-leads standard ECG in the supine position. A paper speed of $25 \mathrm{~mm} / \mathrm{s}$ and a calibration of $10 \mathrm{~mm} / \mathrm{mV}$ were used (Nihon-Kohden, ECG-9010D Japan). All records were evaluated by two special cardiologists for the presence of early repolarization pattern. Patients with complete right bundle branch block (RBBB), complete left bundle branch block (LBBB), J point elevation in V1-V3 leads, long QT interval and arrhythmia, WolfParkinson-White syndrome were not included in the study.

Statistical Analyses: The statistical analyses were performed using the Statistical Package For Social Studies (SPSS version 20.0 USA). P value $<0.05$ was accepted statistically significant.

Received 14-03-2016 Accepted 18-05-2016 Available Online 15-06-2016

1 Balikesir State Hospital, Balikesir Department of Cardiology, Balikesir, Turkey

2 Balikesir State Hospital, Balikesir Department of Cardiovascular Surgery, Balikesir, Turkey

3 Balikesir State Hospital, Balikesir Department of Anesthesiology, Balikesir, Turkey

* Corrospending Author: Tarik Yildirim E-mail: kdrtarik@gmail.com Phone:+90266223510 


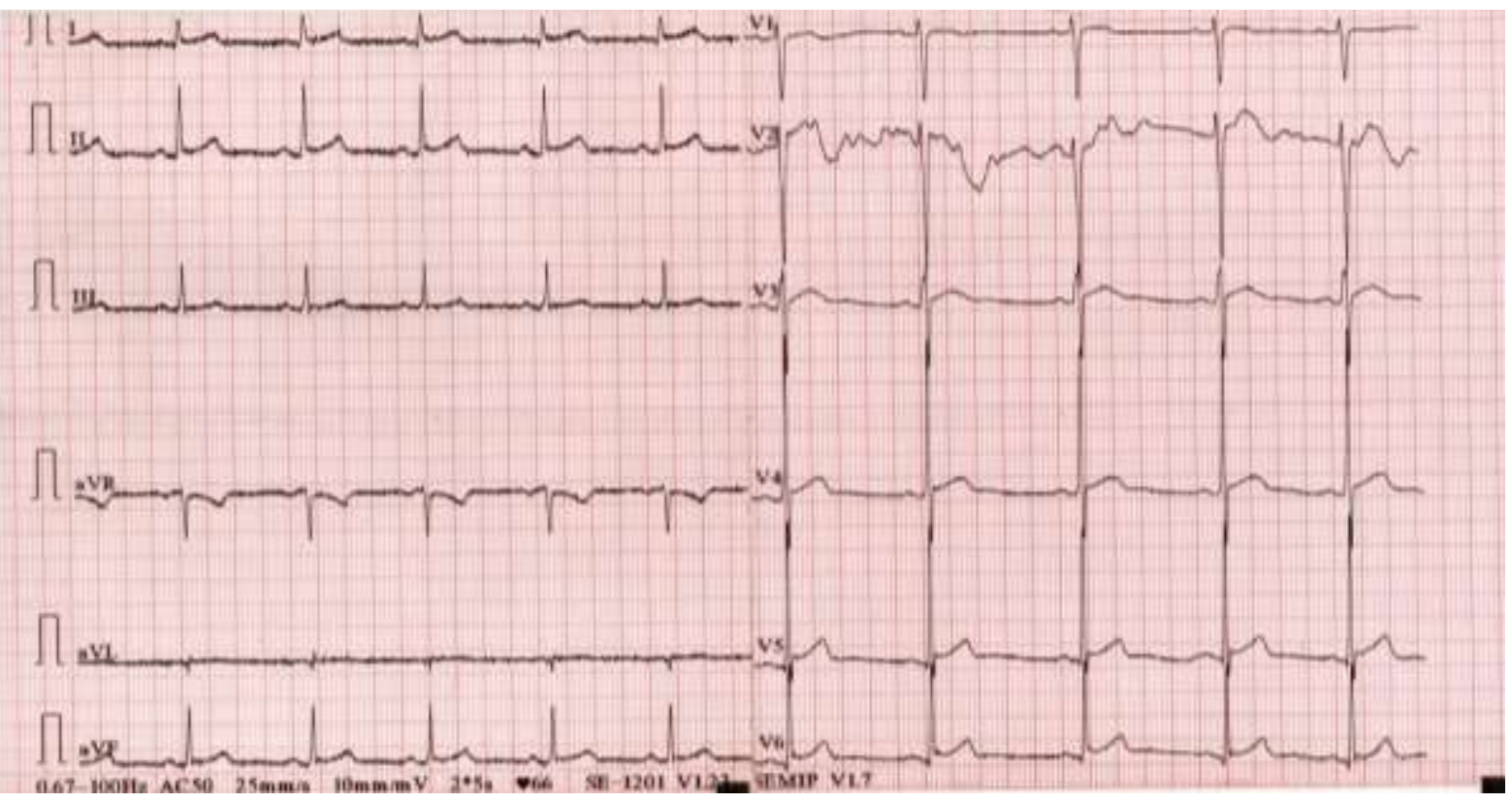

Figure 1. Inferolateral J point elevation

\section{Results}

Ninety-six patients had ER pattern and the prevalence was $23,2 \%$. Of these, individuals with $\mathrm{J}$ point elevation in the inferior, lateral and infero-lateral leads were $61 \quad(14,7 \%), 9(2,2 \%)$ and $26 \quad(15,9 \%)$ respectively. There was no significant difference in QRS duration and PR interval between patients with ER pattern and without it. The ages were similar between patients with ER pattern in different lead pattern (inferior, lateral and infero-lateral leads). Eighty-four subjects had the $\mathrm{J}$ point elevation of 0,1 $\mathrm{mV}$ and 12 subjects had $0,2 \mathrm{mV}$. There was a significant link between heart rate and $\mathrm{J}$ point elevation. When the heart rate was reduced the elevation of $\mathrm{J}$ point was increased significantly. ECG example has been shown in figure 1 .

Table 1. The age range of participants

\begin{tabular}{ccc}
\hline Age & Number* & \% \\
\hline $\mathbf{2 1}$ & 1 & 0,2 \\
$\mathbf{2 2}$ & 11 & 2,7 \\
$\mathbf{2 3}$ & 41 & 9,9 \\
$\mathbf{2 4}$ & 73 & 17,6 \\
$\mathbf{2 5}$ & 80 & 19,3 \\
$\mathbf{2 6}$ & 91 & 22,0 \\
$\mathbf{2 7}$ & 73 & 17,6 \\
$\mathbf{2 8}$ & 44 & 10,6 \\
\hline Total & 414 & 100,0 \\
\hline
\end{tabular}

\section{Discussion}

Haruto et all found the prevalence of ERP in their study $23,9 \%$ and also they claimed that ER pattern was appeared in mostly second decade. Another study conducted by Haisaguerre et all showed the prevalence of $1-13 \%$ and this may result from the intermittent occurrence of ER pattern $(3,11)$. Our results were similar with Haruto`s study. On the other hand, patients enrolled our study were mostly in their second decades and this is confirming the Haruto's finding.

In another study, Tikkanen et all found that the prevalence of ER pattern was 5,8\%. Of them, 3,5\% were seen in inferior leads, $2,4 \%$ in lateral leads and $0,1 \%$ in both leads. They also estimated the incidence of 0,33 when the $\mathrm{J}$ point elevation was greater than 0,2 $\mathrm{mV}$. In that study there was a relation between $\mathrm{J}$ point elevation and prolonged QT interval and this was stronger predictor than left ventricular hypertrophy (13). Our ER pattern prevalence were 14,7\%, 2,2\% and $6,3 \%$ in inferior, lateral and infero-lateral leads respectively.

Siner et all showed that cardiac sudden death occurred 2-4 times more in patients with ER pattern. Also ERP seemed more in inferior and lateral leads in patients with idiopathic VF. Sudden cardiac death rate was high 2,9 times more when the $\mathrm{J}$ point elevation was greater than $0,2 \mathrm{mV}$ and the this rate increased 1,4 times whit the $\mathrm{J}$ point elevation of $0,1 \mathrm{mV}$. J point elevation along with horizontal or descending ST segment increased the rate of death from arrhythmias but up sloping ST segment had benign prognosis $(3,10,12,13)$. Based on these findings, patients with ER pattern should be closely investigated for history of syncope and family history of sudden death. 
ER pattern is affected by autonomic tonus and heart rate and it is related with long QRS duration, short QT duration and left ventricular hypertrophy. It is seen more in male and second decade. The prevalence goes lower after second decade and the reason might be the hormones which change by aging process (14-16).

Although the mechanism of J point and ER pattern are not understood yet completely, Osborn first tried to explain the effect of ions in cell membrane during hypothermia study. After this, another studies showed that the increase repolarization between the endocard and myocardium is responsible for the main pathology (17).

\section{Conclusion}

We report here the prevalence of ERP in young healthy men. Patient with ERP has a higher incidence of ventricular arrhythmia and sudden cardiac death than normal population. We suggest that all young patients with ERP need to be questioned for previous syncope history and family history of sudden cardiac death. More clinical and experimental studies should be performed for explain the relation in ERP and VF.

Conflict of Interest: The authors declare no potential conflicts of interest with respect to the research, authorship, and/or publication of this article.

Ethical issues: All Authors declare that Originality of research/article etc... and ethical approval of research, and responsibilities of research against local ethics commission are under the Authors responsibilities. The study was completed due to defined rules by the Local Ethics Commission guidelines and audits.

\section{Acknowledgement: None}

\section{Reference}

1. Klatsky AL, Oehm R, Cooper RA, Udaltsova $\mathrm{N}$ Armstrong MA. The early repolarization normal variant electrocardiogram: correlates and consequences. Am J Med 2003; 115: 171-7

2. Mehta M, Jain AC, Mehta A. Early repolarization. Clin Cardiol 1999; 22: 59-65.

3. Haissaguerre M, Derval N, Sacher F, Jessel L, Deisenhofe I, de Roy L et al. Sudden cardiac arrest associated with early repolarization. N Engl J Med 2008;358:2016-23.

4. Rosso R, Kogan E, Belhassen B, Rozovski U, Scheinman MM, Zeltser D et al. J-point elevation in survivors of primary ventricular fibrillation and matched control subjects: incidence and clinical significance. J Am Coll Cardiol 2008:52:1231-8
5. Abe A, Ikeda T, Tsukada T, Ishiquro A, Miwa Y, Miyakoshi $\mathrm{M}$ et al. Circadian variation of late potentials in idiopathic ventricular fibrillation associated with $\mathrm{J}$ waves: insights into alternative pathophysiology and risk stratification. Heart Rhythm 2010;7:675-82.

6. Nam GB, Ko KH, Kim J, Park KM, Rhee KS, Choi KJ et al. Mode of onset of ventricular fibrillation in patients with early repolarization pattern vs. Brugada syndrome. Eur Heart J 2010;31:330-9.

7. Derval N, Simpson CS, Birnie DH, Healey JS, Chauan V,Champaqne $\mathrm{J}$ et al. Prevalence and characteristics of early repolarization in the CASPER registry: cardiac arrest survivors withpreserved ejection fraction registry. J Am Coll Cardiol 2011:58:722-8.

8. Rosso R, Adler A, Halkin A, Viskin S. Risk of sudden death among young individuals with $\mathrm{J}$ waves and early repolarization: putting the evidence into perspective. Heart Rhythm 2011;8:923-9.

Benito B, Guasch E, Rivard L, Nattel S. Clinical and mechanistic issues in early repolarization of normal variants and lethal arryhtmia syndromes. J Am Coll Cardiol 2010;56:1177-86.

10. Sinner MF, Reinhard W, Muller M, Beckmann BM, Martens E, Perz S et al. Association of early repolarization pattern on ECG with risk of cardiac and all-cause mortality: a population-based prospective cohort study (MONICA/KORA). PLoS Med 2010;7:e1000314.

11. Haruta D, Matsuo K, Tsuneto A, Ichimaru S, Hida A, Sera $\mathrm{N}$ et al. Incidence and prognostic value of early repolarization pattern in the 12 -lead electrocardiogram. Circulation 2011;123:2931-7.

12. Tikkanen JT, Anttonen O, Junttila MJ, Aro AL, Kerola T, Rissanen HA et al. Long-term outcome associated with early repolarization on electrocardiography. N Engl J Med 2009;361:2529-37.

13. Tikkanen JT, Junttila MJ, Anttonen O, Aro AL, Luttinen S, Kerola $\mathrm{T}$ et al. Early repolarization: electrocardiographic phenotypes associated with favorable long-term outcome. Circulation 2011;123:2666-73.

14. Noseworthy PA, Tikkanen JT, Porthan K, Oikarinen L, Pietila A, Harald K et al. The early repolarization pattern in the general population: clinical correlates and heritability. J Am Coll Cardiol 011;57:2284-9.

15. Sarkozy A, Chierchia GB, Paparella G, Boussy T, De Asmundis $\mathrm{C}$, Roos $\mathrm{M}$ et al. Inferior and lateral electrocardiographic repolarization abnormalities in Brugada syndrome. Circ Arrhythm Electrophysiol 2009;2:154-61. 
16. Watanabe H, Makiyama T, Koyama T, Kannankeril PJ, Seto $\mathrm{S}$, Okamura $\mathrm{K}$ et al. High prevalence of early repolarization in short QT syndrome. Heart Rhythm 2010;7:647-52.
17.

Osborn JJ. Experimental hypothermia; respiratory and blood $\mathrm{pH}$ changes in relation to cardiac function. Am J Physiol 1953;175:389-98.1953;175:389-98.

Copyright (C) 2016 The Author(s); This is an open-access article distributed under the terms of the Creative Commons Attribution License (http://creativecommons.org/licenses/by/4.0), which permits unrestricted use, distribution, and reproduction in any medium, provided the original work is properly cited. All Rights reserved by international journal of Medical Science and Discovery. 